\title{
Analysing the association of dissonance between actual and ideal commute time and commute satisfaction
}

\author{
Dr Runing Ye (corresponding author) \\ Faculty of Architecture, Building and Planning \\ The University of Melbourne \\ Melbourne, VIC 3010 \\ Australia \\ E-mail: runing.ye@unimelb.edu.au \\ Tel: +61390356492 \\ Dr Jonas De Vos \\ Bartlett School of Planning \\ University College London \\ 14 Upper Woburn Place, London WC1H ONN \\ United Kingdom \\ E-mail: jonas.devos@ucl.ac.uk \\ Dr Liang Ma \\ Centre for Urban Research \\ School of Global, Urban and Social Studies \\ RMIT University \\ E-mail: liang.ma@rmit.edu.au \\ Department of Urban and Regional Planning \\ College of Urban and Environmental Sciences \\ Peking University, Beijing, 100871, China
}




\begin{abstract}
Many studies have indicated that commute satisfaction is affected by commute time. However, the dissonance between people's actual and ideal commute time and its effects on travel satisfaction have not been adequately explored in previous research. By using survey data from Xi'an, China, this study examines whether respondents travelling with an ideal commute time will have higher levels of travel satisfaction compared to those travelling with non-ideal commute times. Results from this study, analysing self-reported actual and ideal commute trip durations of 833 respondents, suggest that less than $20 \%$ of the participants travel with their ideal commute time and that the dissonance between actual and ideal commute time has a significant impact on travel satisfaction. Commute satisfaction is highest for respondents travelling with their ideal commuting time, followed by those whose actual commute time is shorter than ideal. Respondents whose actual commute time is longer than the ideal commute time experience the lowest levels of travel satisfaction. Moreover, commute satisfaction decreases when the inconsistency between actual and ideal commute time increases. These results suggest that the effect of commute duration on travel satisfaction might be overestimated and partly mediated by people's preferred commute time. Finally, we also found that the dissonance between actual and ideal commute time significantly differs according to the chosen travel mode, which might partly explain differences in commute satisfaction according to the chosen mode. After controlling for commute time dissonance, the effects of commute time and travel mode on commute satisfaction are weak.
\end{abstract}

Keywords: Travel satisfaction; Actual commute time; Ideal commute time; Dissonance; Travel behaviour 


\section{Introduction}

Due to the mostly derived demand of travel (i.e., reaching spatially separated activities), travel time is often perceived as wasted time, and a cost to be paid to participate in out-of-home activities. Since travel occupies a considerable part of people's daily time budget, this time cannot be spent on other, more desired activities, possibly exerting a negative impact on people's satisfaction with certain life domains and life as a whole (Clark et al., 2019; Stutzer \& Frey, 2008). Not surprisingly, travel (and commuting in particular) is - compared to other daily activities - often perceived rather negatively (e.g., Kahneman et al., 2004). Therefore, transport policies often try to convert 'unproductive' time into (economically) valuable time by focusing on travel time savings (Jain and Lyons, 2008; Lyons et al., 2007; Metz, 2008). However, studies have also indicated that travel itself can have a positive utility, as people might enjoy, for instance, the sensation of speed, the ability to control movement in a demanding and skillful way, the scenery, watching people, and the exposure to the environment (Lyons et al., 2007; Mokhtarian \& Salomon, 2001; Ory \& Mokhtarian, 2005). Jain and Lyons (2008) indicate that travel time can be perceived as a gift rather than a burden, as it can be used (i) to adjust and prepare oneself for the activity ahead ('transition time'), (ii) to 'time out' from work or household obligations, and (iii) to perform certain social, productive or relaxing activities. Studies indicate that travel can positively affect people's subjective well-being through positive emotions experienced during trips (e.g., caused by activities performed during travel), providing access to rewarding activities (e.g., well-paid jobs, leisure activities), and positive spill-over effects of travel on the experience and performance of activities at trip destinations (De Vos et al., 2013; Ettema et al., 2010; Mokhtarian, 2018; Morris \& Zhou, 2018). Due to this positive utility of travel, most people have a nonzero optimum travel time budget and - based on the teleportation test - would not choose to instantaneously teleport themselves to their desired destination if that were an option (Mokhtarian \& Salomon, 2001; Redmond \& Mokhtarian, 2001; Russell \& Mokhtarian, 2015). This liking for travel might also result in trips without a destination ('undirected travel'), such as recreational walking, jogging, or cycling (De Vos et al., 2013; Mokhtarian \& Salomon, 2001).

Due to an increased interest in subjective well-being in multiple disciplines (e.g., Frey, 2018), numerous transport studies have - over the past decade - focused on which emotions people experience during travel and how they evaluate their trips made (De Vos \& Witlox, 2019a). This travel satisfaction can be influenced by certain trip characteristics, such as travel mode choice and trip duration. Studies analysing the effect of trip duration on travel satisfaction indicate that people become less satisfied when trips have longer durations (De Vos, 2019a; De Vos et al., 2016; Ye \& Titheridge, 2015, 2017; Higgins et al., 2018; Lancée et al., 2017; Legrain et al., 2015; Mokhtarian et al., 2015; Morris \& Guerra, 2015a; Olsson et al., 2013; Smith, 2017; St-Louis et al., 2014; Zhu \& Fan, 2018a, 2018b). As a result, it seems that the positive utility of travel is limited and cannot outweigh the perceived negative outcomes of travel (such as less time for other, more productive/rewarding activities). According to Milakis et al. (2015), this utility of travel decreases as trip durations become longer than people's ideal time that they want to spend on travel. However, studies analysing the effect of travel duration on travel satisfaction do not take into account people's preferred travel time. People's actual travel time and preferred travel time might differ and therefore potentially result in lower satisfaction levels. Some studies found that the majority of people are commuting longer than they would like, and that their average actual commute time is considerably longer than their average ideal commute time (LaJeunesse \& Rodríguez, 2012; Páez \& Whalen, 2010; Redmond \& Mokhtarian, 2001). Given that the group of people travelling shorter durations than desired is considerably smaller 
than the group of people travelling longer durations than desired can partly explain overall negative effects of trip duration on travel satisfaction.

Redmond and Mokhtarian (2001) found that people's ideal travel time is strongly and positively correlated with travel-liking attitudes (e.g., liking to explore new places; enjoying travelling/travel time; sensing that travelling is more than just arriving at your destination). Since the well-known theory of cognitive dissonance (Festinger, 1957) indicates that a dissonance between attitudes and behaviour results in feelings of psychological discomfort, it can be expected that an inconsistency between travel-liking attitudes and travel duration will negatively impact travel satisfaction. ${ }^{1}$ Both positive travel-liking attitudes in combination with short travel durations, and negative travel-liking attitudes in combination with long travel durations might result in low travel satisfaction levels. Recently, De Vos (2018) and Ye and Titheridge (2019) found that - focusing on travel mode choice - a dissonance between the chosen travel mode and attitudes towards that mode negatively affects travel satisfaction. The effect of a dissonance between travel liking - or preferred travel time - and actual travel time on travel satisfaction has not been analysed so far.

In this paper we will examine the extent of dissonance between people's actual and ideal commute time - and its effects on commute satisfaction - using 833 respondents from Xi'an, China. In particular, we mainly aim to explore three research questions: (1) what are the factors that affect the ideal commute time, (2) what are the factors that influence a possible dissonance between the actual and ideal commute time, and (3) how does this dissonance influence commute satisfaction. Hence, we want to indicate that the effect of travel duration on travel satisfaction is more complex and probably less negative than generally assumed by existing travel satisfaction studies. It can be hypothesised that travel satisfaction is the highest for people having a similar actual and ideal commute duration; for respondents having either shorter or longer commute durations than desired, travel satisfaction will most likely be lower (Figure 1). The more the actual commute time differs from the ideal commute time, the lower travel satisfaction is expected to be. This will probably especially occur for long travel times as we expect that the group of people having longer travel durations than preferred is larger than those travelling shorter durations than desired. Exploring this research question is important for policies that aim to improve commute satisfaction. If commute time dissonance is a key predictor of commute satisfaction, policy strategies should focus on reducing this dissonance by either adjusting people's commute behaviour or changing their attitudes or expectations regarding commute time, rather than just reducing long commutes. Doing so might not only improve people's mood during commute trips, but also work satisfaction and work performance, which can consequently contribute to their quality of life (e.g., Ettema et al., 2010; De Vos \& Witlox, 2017; Ma \& Ye, 2019). This paper is organised as follows. Section 2 describes the used data and methodology, while Section 3 provides the found results. Finally, a discussion of the main results and a discussion is provided in Section 4.

\footnotetext{
${ }^{1}$ In this study we will not focus on the possible effects of cognitive dissonance on changes in attitudes and behaviour - as the theory of cognitive dissonance indicates is possible - but we will look at how such a dissonance affects satisfaction levels (with travel).
} 


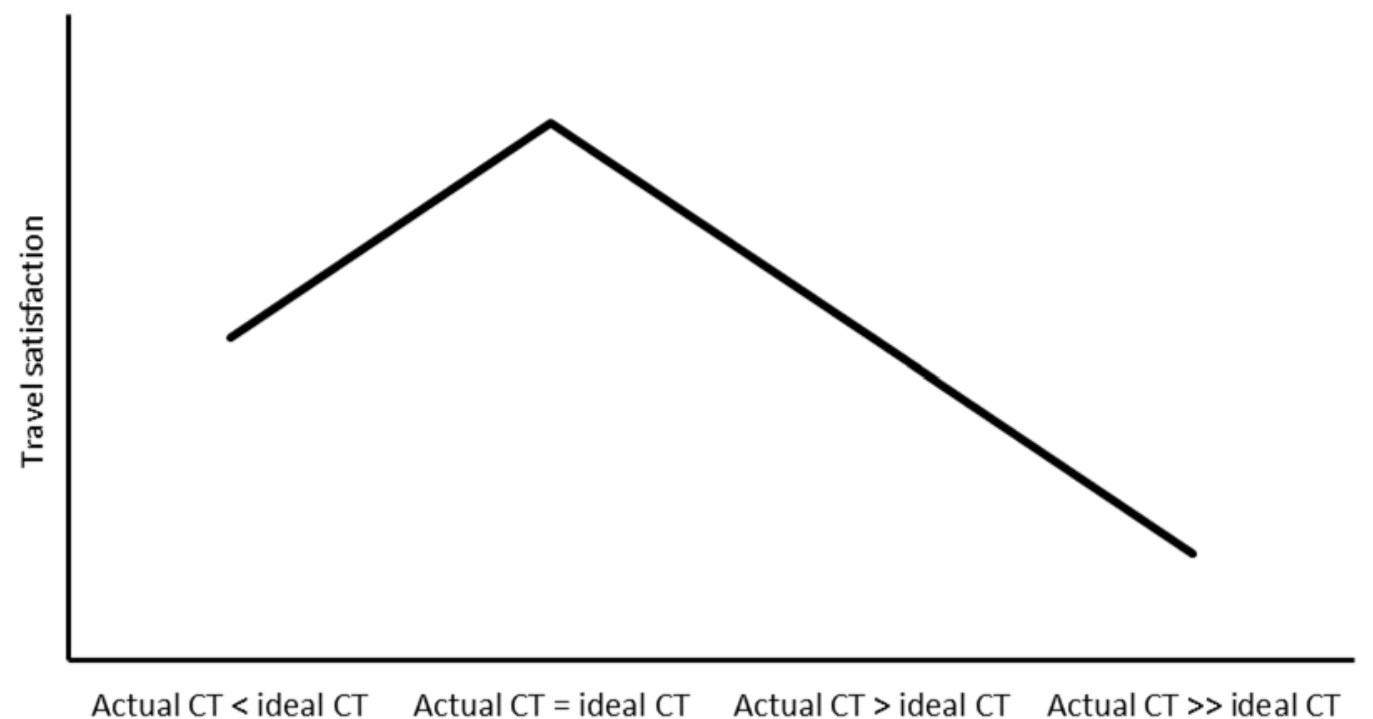

Figure 1. Hypothesised continuum of travel satisfaction according to actual and ideal commute time (CT = commute time).

\section{Methodology}

\subsection{Data}

The data for this study were mainly collected through a self-administered survey conducted between August 20 and November 4, 2018 in Xi'an, China. The survey data collection was first focused on four selected neighbourhoods in Xi'an with relatively low levels of socio-economic status and diverse built environment characteristics. These four neighbourhoods cover typical types of disadvantaged communities in Chinese cities, including a (1) economically depressed community in the inner city, (2) an urban village in the inner suburb, (3) a work-unit yard in the inner suburb and (4) a redeveloped urban village in the inner suburb.

The economically depressed community is a redeveloped shanty town near the city centre. Its residents include both the previous local low-income residents and many urban migrant workers. The urban village is a unique urban form in Chinese cities driven by the fast urbanization. It is usually surrounded by newly-developed high-rise buildings, and associated with low-quality housing conditions and deteriorating public services and facilities. Despite the poor image perceived by the government authorities, the urban village is important in providing affordable housing to rural migrants and disadvantaged local residents (Song et al., 2008). The work unit is another unique type of urban form in Chinese cities, and it is a legacy of planned economy system before the 1980s. The main feature of the work unit is its multifunctional form in land use that includes residence, employment, education and commerce. Most of the daily activities can be completed within the work unit by walking and bicycling. The work units were traditionally owned and operated by government agencies, public service institutions, and state-owned factories. Following the market economy starting from the 1980s, however, many state-owned factories bankrupted and residents living in those work units were unemployed. The work unit we included in this study was a factory bankrupted about 10 years ago, but the original spatial pattern is preserved, and many workers still live there. 
As many of the residents in these disadvantaged neighbourhoods are older adults and already have retired, the survey was also distributed in several selected companies to recruit more full-time workers who make regular commuting trips. The selected employers include a construction company, two consulting firms and a landscape design company. In total, 2,471 survey responses were collected, including 1,459 from the four neighbourhoods and 1,012 from the companies. In the four disadvantaged neighbourhoods, face-to-face interviews with residents were conducted by the corresponding author and trained graduate students. As many participants in these neighbourhoods are older adults with relatively low levels of education, it was difficult for them to complete the surveys themselves. The face-to-face interviews have proven to be an appropriate method in this project, as many respondents asked for clarifications or explanations for some of the survey questions during the data collection process. Employees completed the survey themselves, using paper questionnaires or an online survey link provided to them. A small thank you gift (i.e., a vacuum cup, a plastic basin or an umbrella) was offered to each participant as an incentive.

The initial survey responses were then screened for validity by two methods. Firstly, the time taken for completing the survey must be longer than 18 minutes $^{2}$. Before survey data collection, several tests were conducted by 20 volunteers including both students and employees and the minimum time taken for completing a survey was around 18 minutes. Secondly, a "trap" question ${ }^{3}$ was included in the survey to identify the inattentive respondents. By applying these two conditions, 1,484 valid responses were identified, including 934 from the four neighbourhoods and 564 from the companies. Among the valid responses, 833 are from workers who make regular commute trips, and the majority (68.1\%) of these workers are from the companies. As this study focuses on commute trips, the responses of these 833 workers were used in the following data analysis. Table 1 provides the sample characteristics. In general, the survey captures a variety of working population in Xi'an. The sample is composed of slightly more male than female workers ( $54.4 \%$ vs. $45.6 \%)$, is relatively young $(59.3 \%$ under 35 years old), and well-educated ( $71.7 \%$ with college and above education). Most respondents in this sample have a good health condition (60.7\% BMI: 18.5-24.9; 66.0\% rated good-excellent for health condition), hold a driver license (62.0\%), and own at least one car in their household (67.0\%).

Table 1. Sample characteristics

\begin{tabular}{lrr}
\hline & Number & Percent \\
\hline Age groups & & \\
below 25 & 109 & 13.3 \\
$25-35$ & 377 & 46.0 \\
$35-45$ & 149 & 18.2 \\
$45-55$ & 135 & 16.5 \\
$55-65$ & 44 & 5.4 \\
65 and over & 5 & 0.6 \\
Gender & 375 & 45.6 \\
Female & 447 & 54.4 \\
$\quad$ Male & & 102
\end{tabular}

\footnotetext{
${ }^{2}$ On average, it took the respondents around 33 minutes to complete the survey, and those who failed to meet this criterion only spent an average of 4 minutes on completing the survey, leaving many missing values in their responses.

${ }^{3}$ The trap question is: "This question is for quality assurances purposes for our survey. Please select 'Strongly agree' from following answers". Respondents who did not choose 'Strongly agree' were removed from the sample as they clearly were not focussed on the survey questions.
} 
Completed Secondary School qualification

Completed Technical school

Completed Junior college

Completed Bachelor degree qualification

Completed post-graduate qualification

\section{Household Income}

\begin{tabular}{|c|c|c|}
\hline$¥ 0-¥ 19,999$ per year ( $¥ 1-¥ 1666$ per month) & 84 & 10.2 \\
\hline$¥ 20,000-¥ 39,999 \quad(¥ 1667-¥ 3333)$ & 98 & 11.9 \\
\hline$¥ 40,000-¥ 59,999 \quad(¥ 3334-¥ 5000)$ & 82 & 10.0 \\
\hline$¥ 60,000-¥ 79,999 \quad(¥ 5001-¥ 6666)$ & 58 & 7.1 \\
\hline$¥ 80,000-¥ 99,999 \quad(¥ 6667-¥ 8333)$ & 48 & 5.9 \\
\hline$¥ 100,000-¥ 149,999 \quad(¥ 8334-¥ 12499)$ & 79 & 9.6 \\
\hline$¥ 150,000-¥ 199,999 \quad(¥ 12500-¥ 16666)$ & 24 & 2.9 \\
\hline$¥ 200,000$ and over $\quad(¥ 16667$ and above) & 31 & 3.8 \\
\hline Prefer not to say/don't know & 317 & 38.6 \\
\hline \multicolumn{3}{|l|}{ cars in household } \\
\hline 0 & 271 & 33.0 \\
\hline 1 & 483 & 58.9 \\
\hline 2 & 57 & 7.0 \\
\hline$>2$ & 9 & 1.1 \\
\hline MI & 63 & 7.7 \\
\hline $18.5-24.9$ & 495 & 60.7 \\
\hline $25-29.9$ & 137 & 16.8 \\
\hline 30 and up & 120 & 14.7 \\
\hline \multicolumn{3}{|l|}{ If-reported health } \\
\hline Excellent & 118 & 14.4 \\
\hline Very good & 260 & 31.6 \\
\hline Good & 164 & 20.0 \\
\hline Fair & 248 & 30.2 \\
\hline Poor & 32 & 3.9 \\
\hline \multicolumn{3}{|l|}{ aving driving license } \\
\hline Yes & 510 & 62.0 \\
\hline No & 312 & 38.0 \\
\hline
\end{tabular}

\subsection{Variables}

This study focuses on the dissonance between actual and ideal commute time and its impacts on commute satisfaction. Both actual and ideal commute time were measured by asking the respondents to report their typical one-way commute time and their ideal commute time, and therefore both measures are self-reported. The variable measuring the dissonance between the actual and ideal commute time was created by simply subtracting the actual commute time by ideal commute time.

Commute satisfaction was measured using the Satisfaction with Travel Scale (STS) (De Vos et al., 2015; Ettema et al., 2011). The STS includes measurements on both affective and cognitive components of daily travel. In this study, the respondents were asked to rate the extent they agree with seven items adapted from the STS using a coding scale from -3 to 3 . The seven items include: (1) I felt time was pressed - I felt time was relaxed during the commute; (2) I was worried I would not be in time - I was confident I would be in time; (3) I was stressed - I was calm; (4) I was tired - I was alert; (5) I was bored - I was enthusiastic; (6) I think this commute is the worst I can think of - I think this commute is the best I can think of; (7) I think this commute went well - I think this commute did not go well. Since the 
internal consistency of the seven items can be considered as good (Cronbach's alpha is 0.926), we created a variable representing commute satisfaction by averaging the scores on the seven items.

Other commuting-related variables measured in this study include commute distance and commute mode choice. The commute distance was measured by asking the respondents to approximate the distance between their home and workplace. For commute mode, the respondents were asked to report their primary travel mode used for a typical commute trip, i.e., the mode used for the longest duration of the commute trip. In case two or more travel modes were used for a considerable time during the commute, the respondents could choose multiple primary modes. About $50 \%$ of the respondents chose more than one primary travel mode. The original travel mode options in the survey include thirteen modes, including bike, bike-share, e-bike, e-bike share, worker bus, walk, metro, bus, car, taxi, ridesharing services (e.g., DiDi, CaoCao), car-sharing with friends and family, and working from home. For simplicity, these modes were aggregated into three modes: active travel (bike, bikeshare, e-bike, e-bike share, walk), transit (metro, bus, worker bus), and car (car, taxi, ridesharing service, car-sharing with friends and family). People indicating to work from home were excluded from the sample. Respondents were then divided into the following six groups: active travel (27.4\%), Transit (22.7\%), Car (11.5\%), Active travel + Car (2.0\%), Active travel + Transit (20.8\%), Car + Transit (15.6\%).

We also measured attitudes towards travel by asking respondents to which extent they agree on 27 statements, which were adapted from Handy et al. (2005). In this study, we only focus on statements referring to attitudes towards travel in general, i.e.: "Travel time is generally wasted time", "The only good thing about traveling is arriving at your destination", and "Getting there is half the fun". The questions were coded by using a 5-point Likert scale from strongly disagree (1) to strongly agree (5). Table 2 presents descriptive statistics for all variables used in the paper.

\subsection{Analysis Methods}

As stated in the introduction section, this study mainly aims to explore three research questions: (1) what are the factors that affect the ideal commute time, (2) what are the factors that influence a possible dissonance between the actual and ideal commute time, and (3) how does this dissonance influence commute satisfaction. For the first question, an Ordinary Least Squares (OLS) model was estimated to examine possible factors associated with the ideal commute time. For the second question, descriptive analyses were first conducted to examine the preliminary patterns of the relationships between commute time dissonance and the possible influencing factors, such as sociodemographics, travel modes, actual commute time, and attitudes towards travel. Regression models were then developed to predict the dissonance with such influencing factors. Different model specifications for the dissonance were tested at the beginning. This includes an OLS model to predict the dissonance between actual and ideal commute time, an ordered logit model and a multinomial logit model to predict the dissonance groups. For the latter model, the respondents were divided into three groups, including those who prefer a longer commute duration (i.e., actual < ideal time), those who commute with their ideal commute time (i.e., actual = ideal time), and those who prefer a shorter commute duration (i.e., actual > ideal time). Both the OLS model and the ordered logit model assume that there is an intrinsic ordering nature from the 'actual<ideal' to the 'actual>ideal', but this is not necessarily the case. For example, those in the matched group (i.e., 'actual=ideal') do not have a higher level of dissonance than those in the 'actual<ideal' group. We therefore chose to use a multinomial logit model to predict the factors that determine the respondents falling into different dissonance groups. Regarding the third research question, we applied an OLS model to predict commute satisfaction with dissonance groups as independent variables. Considering the censoring nature of the 
dependent variable (i.e., commute satisfaction), we also estimated a Tobit model, but the results were quite similar with the OLS model. In this paper, we only present the results of the OLS model for the easy interpretation of the coefficients.

\section{Results and Discussion}

\subsection{Ideal commute time}

An OLS model was first estimated to predict the ideal commute time, and the results are presented in Table 2. Overall, the included variables explained about $29 \%$ of the variations in the ideal commute time. Among the independent variables included in the model, the most important (based on the standardised coefficient) explanatory variable is actual commute time, which is positively associated with the ideal commute time. The strong correlation between actual and ideal commute time indicates some levels of cognitive consonance, people either managed their daily commute to achieve the ideal commute time or they changed their ideal time to be consistent with their actual commute time. Among the three attitudinal variables, only "Travel time is wasted time" was significantly associated with the ideal commute time, suggesting that those holding a negative attitude towards travel time tend to have a shorter ideal commute time. Further, while commuters using different travel modes showed slight differences in the ideal commute time, most of these differences were not statistically significant. Only the multimodal commuters using both car and transit had an ideal commute time significantly longer than active travel commuters (i.e., 3.4 minutes). Finally, most sociodemographic characteristics do not explain variations in ideal commute time; only the health condition of commuters was positively associated with ideal commute time.

Table 2. OLS model for ideal commute time

\begin{tabular}{lrrrr}
\hline & Coef. & Std. Err. & $\mathrm{t}$ & $\mathrm{P}>\mathrm{t}$ \\
\hline Age & -0.062 & 0.045 & -1.380 & 0.169 \\
Female & 1.289 & 0.816 & 1.580 & 0.115 \\
Education & 0.241 & 0.337 & 0.720 & 0.475 \\
\#Cars in HH & -0.045 & 0.364 & -0.120 & 0.902 \\
Health & 0.725 & 0.346 & 2.100 & 0.036 \\
Commute mode & & & \\
$\quad$ Active travel & & & \\
$\quad$ Transit & Ref. & & 1.440 & 0.151 \\
$\quad$ Car & 2.030 & 1.411 & 0.494 \\
$\quad$ Active travel+Car & -1.212 & 1.771 & -0.680 & 0.427 \\
$\quad$ Active travel+Transit & 2.422 & 3.043 & 0.800 & 0.050 \\
$\quad$ Car+Transit & 2.446 & 1.245 & 1.970 & 0.019 \\
Attitudes: Travel time is wasted time & 3.417 & 1.452 & 2.350 & 0.021 \\
Attitude: The only good thing about travelling is & -0.942 & 0.407 & -2.310 & 0.827 \\
Attitude: Getting there is half the fun & -0.090 & 0.413 & -0.220 & 0.334 \\
Commute time & 0.418 & 0.432 & 0.970 & 0.000 \\
Constant & 0.174 & 0.020 & 8.590 & 0.001 \\
\hline Number of obs. & 13.188 & 3.893 & 3.390 & \\
R-squared & 570 & & & \\
\hline
\end{tabular}

\footnotetext{
${ }^{4}$ Active travel was used as the reference in this and following models, as we hypothesize that active travel commuters had the shortest ideal commute time, least level of dissonance on actual and ideal commute time, and highest level of commute satisfaction, comparing with other commuting modes users.
} 


\subsection{Dissonance between ideal and actual commute time}

Figure 2 illustrates the distribution of respondents' actual and ideal commute time. There is a significant variation of the actual one-way commute time (mainly ranging from 0 to 65 minutes), while the ideal one-way commute time is primarily distributed within 35 minutes. The 30-34 minutes category is the most reported ideal commute time, followed by the 20-24 minutes category and the 10-14 minutes category. Ideal commute times slightly differ from results found by Páez and Whalen (2010) and Redmond and Mokhtarian (2001), who indicated that respondents' ideal commute time is mostly between 10 and 20 minutes.

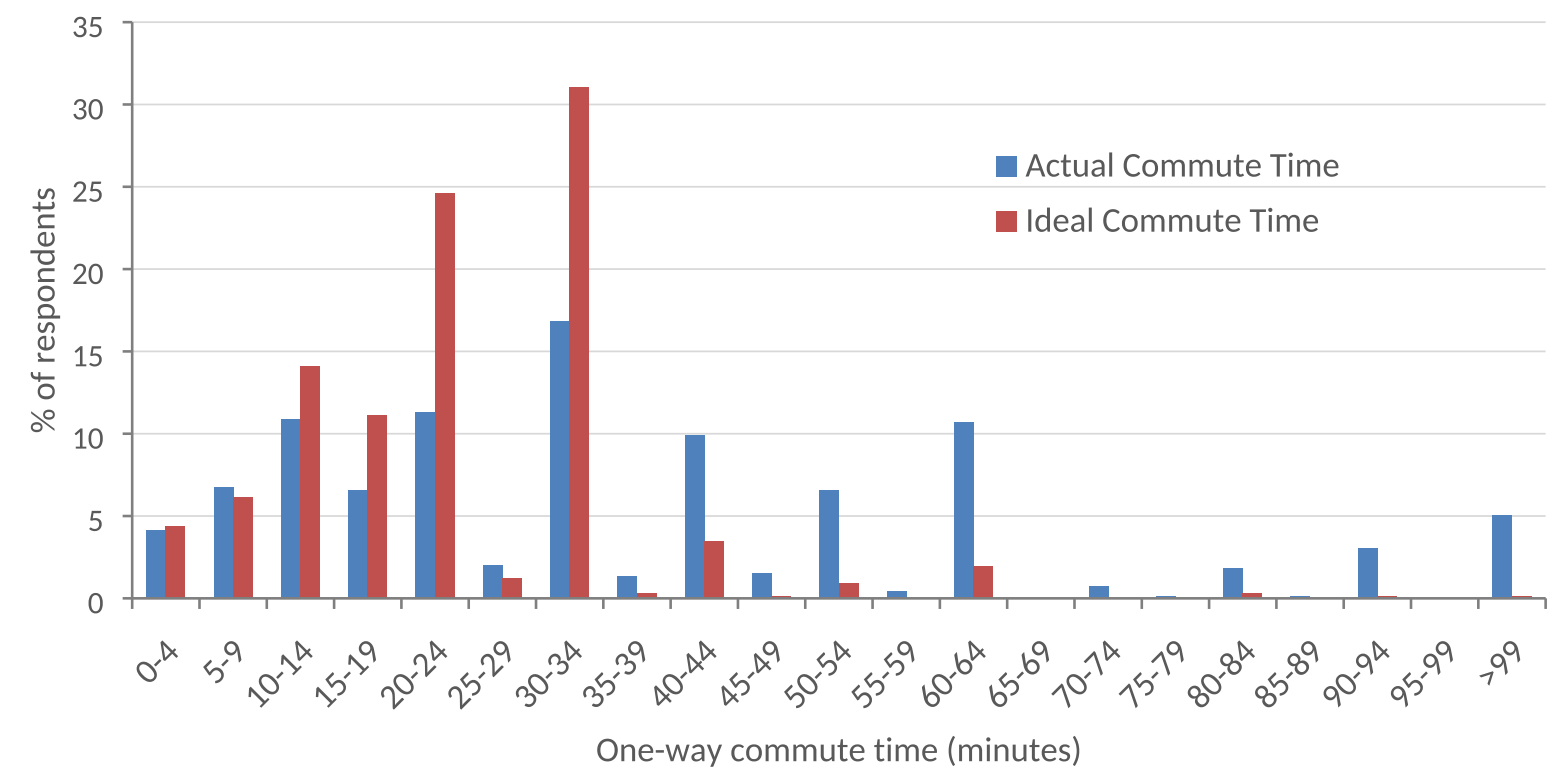

Figure 2. Distribution of ideal and actual commute time

Figure 3 and Table 3 illustrate the correlation between the actual and ideal commute time according to the used travel mode(s). The $45^{\circ}$ line represents a situation in which the actual commute time is equal to the ideal commute time. The area under this line indicates that the actual commute time is longer than the ideal commute time, while the area above this line indicates that the actual commute time is shorter than ideal commute time. It is clear that most respondents (64\%) fall into the area under the $45^{\circ}$ line, indicating that for most respondents the actual commute time is longer than their ideal commute time. However, a considerable share (about 17\%) of the respondents is located above the line, suggesting that these respondents prefer to commute for a longer time than their current commute time. These results are comparable to results found by Páez and Whalen (2010) and Redmond and Mokhtarian (2001) and suggest that - at least for a certain part of the population travel has a positive utility. Finally, about $19 \%$ of the respondents has a commute time that is consistent with their ideal commute time.

Interestingly, the relationship between actual and ideal commute time varies significantly according to the used commute mode(s). Especially transit and car commuters are located below the $45^{\circ}$ line, while active travellers are often located above the line (see Appendix for scatter plots of each mode (group) separately). Table 3 provides a more detailed picture of this pattern. Commuters walking or cycling are more or less equally distributed into the three groups based on actual and ideal commute time; $38.4 \%$ has a commute time equal to the desired commute time, $35.5 \%$ has a shorter than ideal commute time, and $26.1 \%$ has a longer than ideal commute time. For respondents commuting by 
transit or car, however, $84.2 \%$ reports a longer than ideal commute time. The amount of transit and car users having a commute time equal or shorter than ideal are limited $(6.5 \%$ and $9.3 \%$ for transit users and $7.9 \%$ and $7.9 \%$ for car users, respectively). For respondents using more than one travel mode for their commute, less than half of respondents combining active travel with car use (44.4\%) have a longer than ideal commute time. Respondents combining active travel with transit, and especially those combining car with transit, mostly have a longer than desired commute duration $169.3 \%$ and $86.0 \%$, respectively).

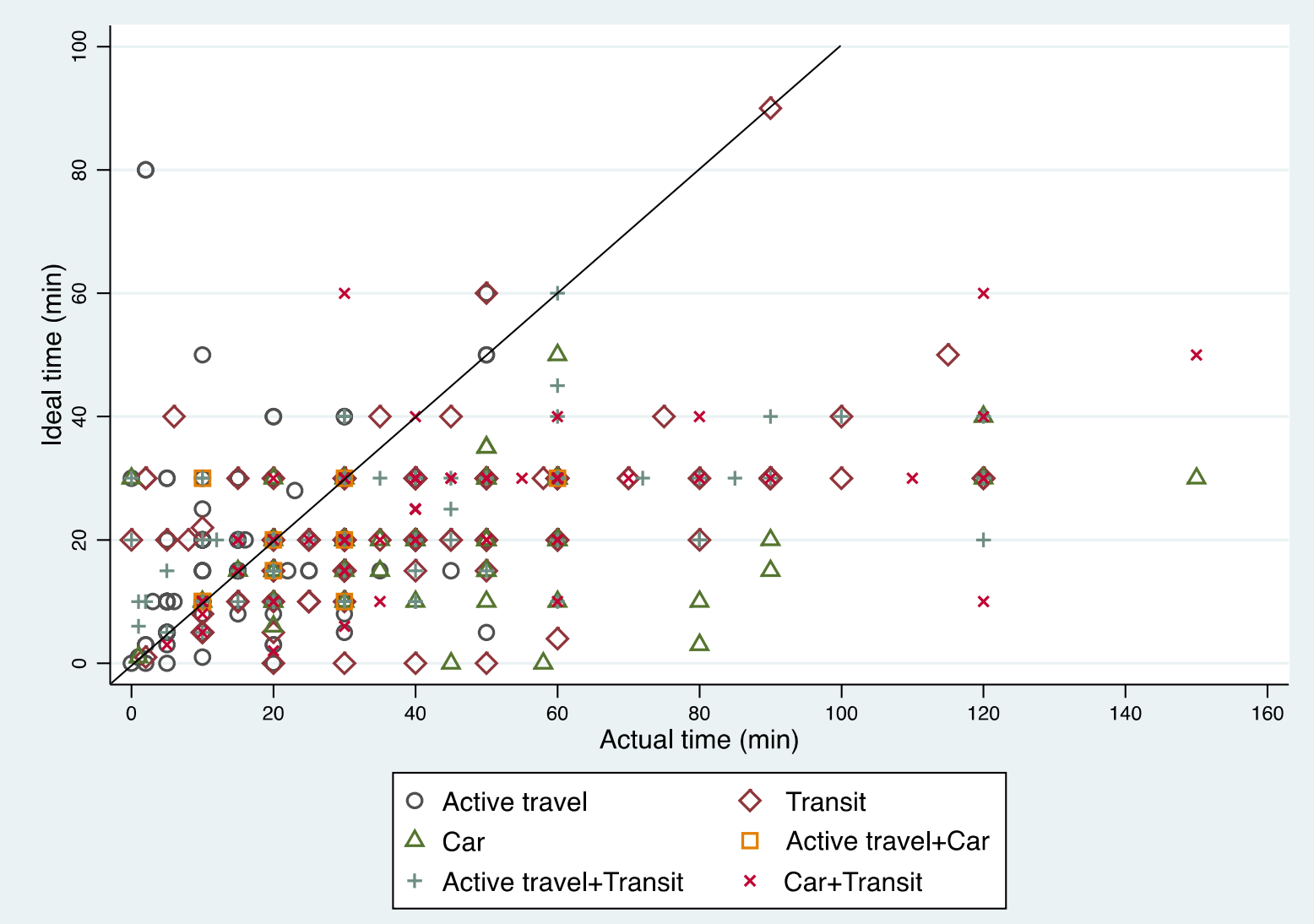

Figure 3. Scatter-plot of ideal versus actual commute time by commute modes

Table 3. Dissonance between actual and ideal commute time by commute modes

\begin{tabular}{|c|c|c|c|c|c|c|c|}
\hline & $\begin{array}{l}\text { Active } \\
\text { travel }\end{array}$ & Transit & Car & $\begin{array}{c}\text { Active } \\
\text { travel + } \\
\text { Car }\end{array}$ & $\begin{array}{c}\text { Active } \\
\text { travel + } \\
\text { Transit }\end{array}$ & $\begin{array}{c}\text { Car + } \\
\text { Transit }\end{array}$ & Total \\
\hline \multirow{2}{*}{ Actual< $<$ deal commute time } & 61 & 13 & 5 & 1 & 20 & 4 & 104 \\
\hline & $35.5 \%$ & $9.3 \%$ & $7.9 \%$ & $11.2 \%$ & $15.7 \%$ & $4.0 \%$ & $17.1 \%$ \\
\hline \multirow{2}{*}{ Actual=Ideal commute time } & 66 & 9 & 5 & 4 & 19 & 10 & 113 \\
\hline & $38.4 \%$ & $6.5 \%$ & $7.9 \%$ & $44.4 \%$ & $15.0 \%$ & $10.0 \%$ & $18.5 \%$ \\
\hline \multirow{2}{*}{ Actual>Ideal commute time } & 45 & 117 & 53 & 4 & 88 & 86 & 393 \\
\hline & $26.1 \%$ & $84.2 \%$ & $84.2 \%$ & $44.4 \%$ & $69.3 \%$ & $86.0 \%$ & $64.4 \%$ \\
\hline Total & 172 & 139 & 63 & 9 & 127 & 100 & 610 \\
\hline
\end{tabular}

Note: Because of the missing values in the actual and ideal commute time variables, the sample size reduces to 610 in this table. 
Figure 4 shows the average actual and ideal commute time for different commute modes. For all travel modes, the average ideal travel time is more or less the same - i.e., around 20 minutes - while the actual commute time significantly differs according to the chosen travel mode, ranging from 18 minutes for active travel to 49 minutes for car use. These actual and ideal commute time for various modes are similar as those found by Milakis et al. (2015). Paired sample t-tests were conducted to examine whether the differences between the mean actual and mean ideal time for each mode are statistically significant. For active travel and active travel + car commuters, the actual commute time is quite similar to the ideal commute time, and the t-tests indicate no significant differences (at $\mathrm{p}<$ 0.05). For transit, car, active + transit, and transit + car commuters, the actual commute time is significantly longer than the ideal commute time (at $p<0.05$ ).

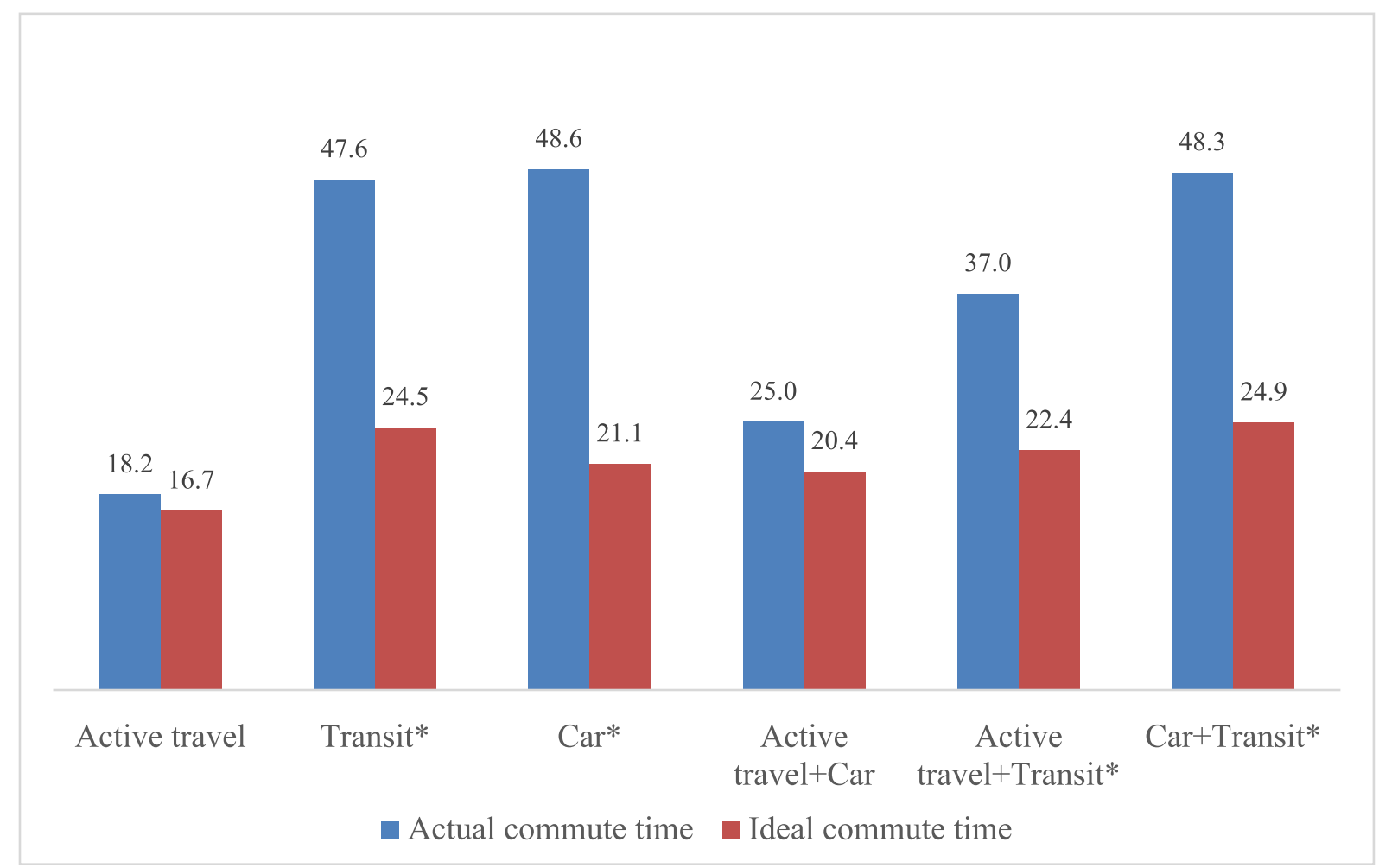

Figure 4. Actual and ideal commute time (minutes) by commute modes $\left({ }^{*}=\right.$ significantly different at $p<0.05)$

Figure 5 illustrates the relationship between attitudes towards travel and dissonance between actual and ideal commute time. Respondents whose actual commute time is longer than ideal rated a higher score on "Travel time is wasted time" than the respondents whose actual commute time is equal or shorter than ideal commute time. The ANOVA test indicates that this difference is statistically significant $(F=3.28, p<0.05)$. This suggests that respondents having a longer commute time than desired really have an urge to reduce their commute time, as they tend to find it wasted time. For the statements "Getting there is half the fun", and "The only good thing about travelling is arriving at your destination" the ANOVA tests indicated that the differences of scores between dissonance groups were not statistically significant. Overall, the three dissonance groups do not show great variation in attitudes towards travel. 


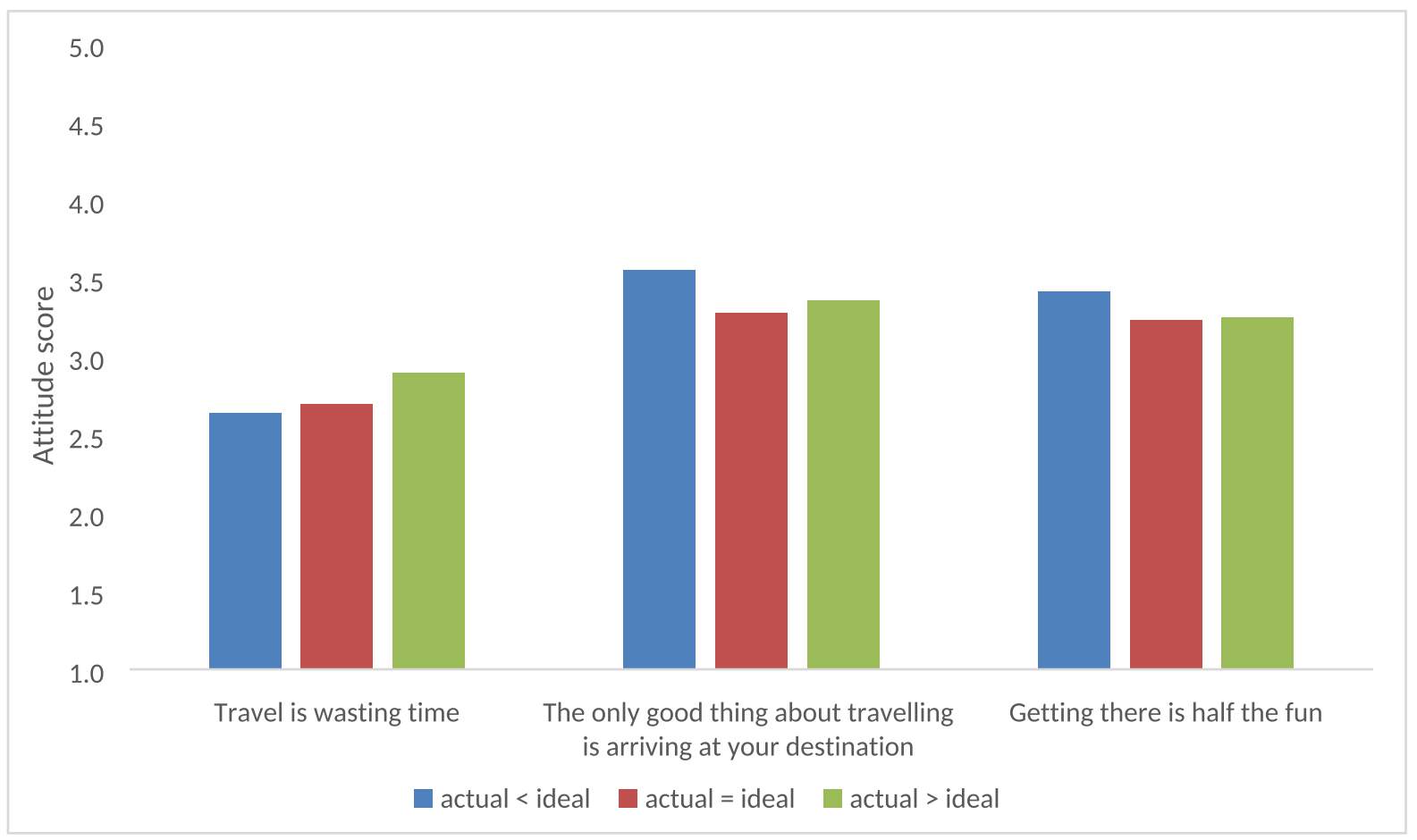

Figure 5. Attitudes towards travel by dissonance group

A multinomial logit model was estimated to examine the factors explaining membership of the three dissonance groups (actual=ideal, actual<ideal, and actual>ideal). The model results are presented in Table 4. The likelihood ratio chi-square of 326.225 with a $p$-value $<0.01$ suggests that the model as a whole fits significantly better than an empty model. The reference group contains the respondents whose actual commute time equals their ideal commute time (actual = ideal). Accordingly, the interpretation of the coefficient in one group is the relative probability of being in that group versus in the reference group (actual = ideal). As shown in the table, the factors associated with being in 'actual<ideal' and 'actual>ideal' groups are quite different. It seems that socio-demographic characteristics and travel attitudes are more important in predicting that respondents belong to the 'actual<ideal' group, while commuting characteristics are more important in predicting respondents to be in the 'actual>ideal' group.

The model results suggest that younger adults and those with good health condition (marginally significant) are more likely to be in the 'actual<ideal' group than in the matched group. However, none of the socio-demographic variables were statistically significant in predicting the 'actual>ideal' group. Additionally, none of the commute modes were statistically significant in predicting the 'actual<ideal' group, while they were significant in predicting the 'actual>ideal' group. In particular, transit commuters had the highest probability falling into the 'actual>ideal' group, followed by car commuters, and multimodal commuters using both car and transit. In terms of travel attitudes, only one attitudinal variable ("The only good thing about travelling is arriving at your destination") was positively and significantly associated with the possibility being a member of the 'actual<ideal' group. This association is unexpected because it can be assumed that those in the 'actual<ideal' group would have a positive attitude towards travel. Finally, commuting time is negatively associated with being in the 'actual<ideal' group and positively associated with being in the 'actual>ideal' group. Not surprisingly, people with a long commute time are more likely to have a longer actual commute time than ideal commute time. 
Table 4. Multinomial logit model for dissonance between actual and ideal commute time (Ref: 'Actual=|deal')

\begin{tabular}{|c|c|c|c|c|c|c|}
\hline & \multicolumn{3}{|c|}{ 'actual<ideal' } & \multicolumn{3}{|c|}{ 'actual>ideal' } \\
\hline & Coef. & $\mathrm{z}$ & $P>Z$ & Coef. & $z$ & $P>Z$ \\
\hline Age & -0.033 & -2.270 & 0.023 & 0.009 & 0.660 & 0.510 \\
\hline Female & -0.059 & -0.190 & 0.849 & -0.436 & -1.560 & 0.119 \\
\hline Education & 0.017 & 0.160 & 0.873 & 0.055 & 0.550 & 0.585 \\
\hline \#Cars in $\mathrm{HH}$ & 0.082 & 0.400 & 0.693 & 0.013 & 0.070 & 0.945 \\
\hline Health & 0.225 & 1.700 & 0.089 & 0.062 & 0.500 & 0.616 \\
\hline \multicolumn{7}{|l|}{ Commute mode } \\
\hline Active travel & Ref. & & & Ref. & & \\
\hline Transit & 0.409 & 0.790 & 0.429 & 1.859 & 4.090 & 0.000 \\
\hline Car & -0.260 & -0.330 & 0.741 & 1.229 & 2.110 & 0.035 \\
\hline Active travel+Car & -1.163 & -1.000 & 0.316 & -0.404 & -0.440 & 0.657 \\
\hline Active travel+Transit & 0.244 & 0.610 & 0.543 & 0.983 & 2.610 & 0.009 \\
\hline Car+Transit & -0.667 & -1.020 & 0.309 & 1.156 & 2.540 & 0.011 \\
\hline Attitudes: Travel time is wasted time & -0.167 & -1.210 & 0.228 & 0.052 & 0.390 & 0.696 \\
\hline $\begin{array}{l}\text { Attitude: The only good thing about } \\
\text { travelling is arriving at your }\end{array}$ & & & & & & \\
\hline destination & 0.290 & 1.980 & 0.048 & 0.156 & 1.150 & 0.251 \\
\hline Attitude: Getting there is half the fun & 0.241 & 1.490 & 0.137 & 0.050 & 0.330 & 0.745 \\
\hline Actual commute time & -0.027 & -1.910 & 0.056 & 0.072 & 6.560 & 0.000 \\
\hline Constant & -0.509 & -0.420 & 0.677 & -3.079 & -2.690 & 0.007 \\
\hline Number of Obs. & 576 & & & & & \\
\hline LR chi2 & 326.225 & & & & & \\
\hline Prob > chi2 & $<0.001$ & & & & & \\
\hline McFadden's R2 & 0.313 & & & & & \\
\hline
\end{tabular}

\subsection{Dissonance between ideal and actual commute time and commute satisfaction}

Figure 6 illustrates the relationship between commute time dissonance and commute satisfaction. The results align well with our hypothesis that commuters with a dissonance between actual and ideal commute time (in either direction) have lower levels of commute satisfaction compared to those having a similar actual and ideal commute time. The larger the extent of the dissonance, the lower commute satisfaction is. A One-way ANOVA test was conducted and the results ( $F=18.05, p<0.05$ ) indicate that the differences in commute satisfaction between different levels of dissonance were statistically significant. In sum, the results found largely confirm our hypothesis as demonstrated in Figure 1. 


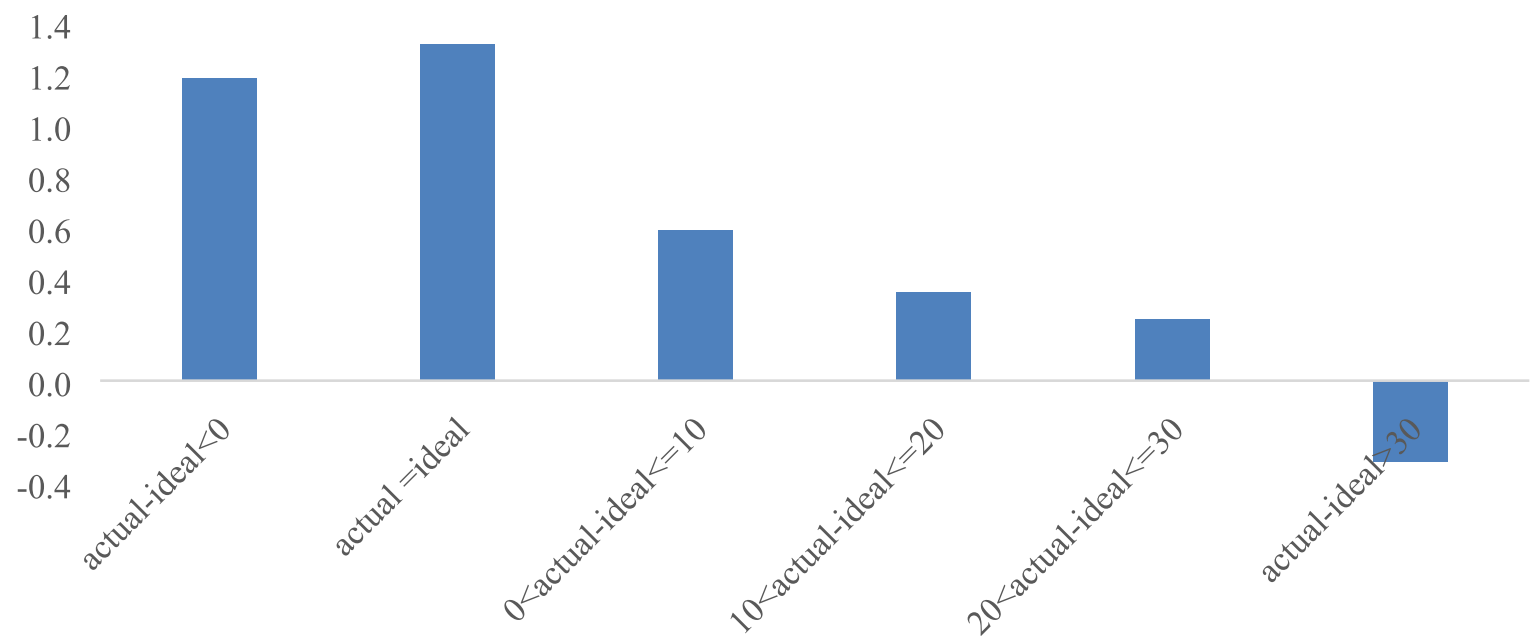

Figure 6. Commuting satisfaction by dissonance groups

OLS models were further estimated to investigate the factors associated with commute satisfaction. To better understand the role of the dissonance between actual and ideal commute time on commute satisfaction, an OLS model without the dissonance group variable was first estimated, and a second OLS model including the dissonance group variables was then followed. Table 5 presents the model results. The first model includes the typical commuting variables such as commute time and modes as has been done in previous studies on travel satisfaction, and results are also quite consistent with previous research. The results show that commute time is negatively associated with commute satisfaction, and active travel commuters have the highest level of commute satisfaction compared to those using other travel modes, such as car and transit. Further, the results suggest that older people and those who report good health conditions have higher levels of commute satisfaction. In the second model we added dissonance variables (i.e., six dissonance groups as shown in Figure 6). The results of model 2 show that the variable commute time becomes only marginally significant, and three of the four dummies for the commuting modes become insignificant after controlling for the dissonance variables, suggesting that the dissonance between the actual and ideal commute time mediates the effects of the commute time and modes on commute satisfaction.

Regarding the dissonance group variables, an 'actual >ideal' dissonance was negatively associated with commute satisfaction. While a negative association was also revealed between a 'actual<ideal' dissonance and commute satisfaction, it was not statistically significant. Furthermore, we find that even when controlling for the dissonance between actual and ideal commute time - the actual commute time still has a marginally significant negative effect (at $0.05<p<0.1$ ) on commute satisfaction. Both the dissonance variable and actual commute time were statistically significant in the model, suggesting that they have independent effects on commute satisfaction. In terms of the attitudinal variables, only "Getting there is half the fun" was positively associated with commute satisfaction, indicating that those holding a positive attitude towards travel are more likely to have a higher level of commute satisfaction. 
Table 5. OLS model for commute satisfaction

\begin{tabular}{|c|c|c|c|c|c|c|}
\hline & \multicolumn{3}{|c|}{ Model 1} & \multicolumn{3}{|c|}{ Model 2} \\
\hline & Coef. & $\mathrm{t}$ & $P>t$ & Coef. & $\mathrm{t}$ & $P>t$ \\
\hline Age & 0.012 & 2.100 & 0.037 & 0.014 & 2.290 & 0.023 \\
\hline Female & 0.034 & 0.280 & 0.778 & 0.001 & 0.010 & 0.991 \\
\hline Education & -0.064 & -1.340 & 0.181 & -0.054 & -1.120 & 0.262 \\
\hline \#Cars in $\mathrm{HH}$ & 0.026 & 0.370 & 0.710 & 0.035 & 0.500 & 0.617 \\
\hline Health & -0.205 & -3.960 & 0.000 & -0.202 & -3.910 & 0.000 \\
\hline \multicolumn{7}{|l|}{ Dissonance group } \\
\hline actual=ideal & & & & Ref. & & \\
\hline actual-ideal $<0$ & & & & -0.013 & -0.070 & 0.946 \\
\hline $0<$ actual-ideal $<=10$ & & & & -0.451 & -2.400 & 0.017 \\
\hline $10<$ actual-ideal $<=20$ & & & & -0.482 & -2.270 & 0.024 \\
\hline $20<$ actual-ideal $<=30$ & & & & -0.421 & -1.640 & 0.101 \\
\hline actual-ideal>30 & & & & -0.660 & -1.970 & 0.049 \\
\hline Actual commute time & -0.011 & -5.120 & 0.000 & -0.007 & -1.920 & 0.056 \\
\hline \multicolumn{7}{|l|}{ Commute mode } \\
\hline \multicolumn{7}{|l|}{ Active travel } \\
\hline Transit & -0.626 & -3.510 & 0.000 & -0.448 & -2.370 & 0.018 \\
\hline Car & -0.520 & -2.230 & 0.026 & -0.352 & -1.470 & 0.143 \\
\hline Active travel+Car & -0.479 & -0.960 & 0.336 & -0.484 & -0.970 & 0.330 \\
\hline Active travel+Transit & -0.356 & -2.020 & 0.044 & -0.238 & -1.320 & 0.189 \\
\hline Car+Transit & -0.408 & -2.070 & 0.039 & -0.260 & -1.260 & 0.207 \\
\hline Attitudes: Travel time is wasted time & -0.035 & -0.620 & 0.539 & -0.028 & -0.500 & 0.618 \\
\hline Attitude: The only good thing about & -0.027 & -0.440 & 0.658 & -0.022 & -0.360 & 0.720 \\
\hline Attitude: Getting there is half the fun & 0.239 & 3.560 & 0.000 & 0.238 & 3.560 & 0.000 \\
\hline Constant & 1.204 & 2.340 & 0.020 & 1.143 & 2.190 & 0.029 \\
\hline Number of obs. & 570 & & & 570 & & \\
\hline R-squared & 0.216 & & & 0.229 & & \\
\hline
\end{tabular}

\section{Conclusion}

This study examined the dissonance between the actual and ideal commute time and its effects on commute satisfaction using survey data from Xi'an, China. Although the relationship between commute time and commute satisfaction seems well established, this study contributes to the previous literature by including the inconsistency between the actual commute time and ideal or preferred commute time. Based on the theories of positive utility of travel and cognitive dissonance, we assume that people travelling with their ideal commute time would have a higher level of commute satisfaction compared to those travelling either longer or shorter times than preferred, irrespective of actual commute duration or distance. This study first explored the factors that influence the ideal commute time. Results indicate that the actual commute time is the most important factor that affects the ideal commute time. This indicates that, to some extent, most people manage to reach a consonance between the actual and ideal commute time by either adjusting their actual commute time (i.e., adjusting behaviour) or changing their ideal commute time (i.e., adjusting expectations or attitudes), to maximise their satisfaction with the commute. This aligns well with the cognitive dissonance theory (Festinger, 1957). Furthermore, people with a negative attitude towards travel tend to have a shorter ideal commute time.

This study then examined the factors that contribute to the dissonance between actual and ideal commute time. We found that a majority (nearly two thirds of the respondents) of the commuters 
travels longer durations than preferred, while $17 \%$ of the commuters travels shorter times than preferred, suggesting a certain level of positive utility of travel. This study also found that people with a long travel duration (especially those with a one-way commute of 60 minutes or more) are more likely to experience a dissonance between actual and ideal commute time (i.e., actual>ideal time). Interestingly, people walking and bicycling have the smallest - and even insignificant - gap between actual and ideal commute time, and are least likely to experience a dissonance, compared to those commuting by transit or car. These results can help explain why commute satisfaction differs according to the chosen travel mode. Numerous studies have indicated that active travel mostly results in the highest levels of travel satisfaction, while public transport users are often dissatisfied (e.g., De Vos et al., 2016; Mokhtarian et al., 2015; Morris \& Guerra, 2015b; St-Louis et al., 2014; Ye \& Titheridge, 2017; Zhu \& Fan, 2018a). However, why travel satisfaction differs according to which travel mode has been used, is currently lacking (De Vos, 2019b). The difference in the extent of commute time dissonance according to the chosen travel mode might partly explain differences in commute satisfaction. A high level of consistency between the actual and ideal commute duration of active travellers could result in high travel satisfaction levels, while the existing commute time dissonance of motorised travellers might result in relatively low satisfaction levels. As a result, it might not be the characteristics of a certain travel mode that determine satisfaction levels, but the level of dissonance between actual and ideal commute time; which considerable differs between various travel modes. Regarding the roles of travel attitudes on commute time dissonance, this study found that the effects of the three attitudinal variables are rather weak.

This study finally investigated the effects of the dissonance between the actual and ideal commute time on commute satisfaction. Consistent with our hypothesis, this study found a significant association between commute time dissonance and commute satisfaction. In particular, a 'actual>ideal' dissonance is negatively associated with commute satisfaction, and the larger the dissonance, the lower the commute satisfaction is. Somewhat surprisingly, we did not find a significant difference in commute satisfaction between those in the 'actual<ideal' group and the consonant group, although the descriptive analysis shows a lower level of commute satisfaction for the 'actual<ideal' group compared to the consonant group. This suggests that travelling a shorter duration than ideal is perceived less negative compared to travelling a longer duration than ideal. Further, this study found that the dissonance between actual and ideal commute time mediates the effects of commute time and travel modes on commute satisfaction, although the duration of the commute still has a modest independent/direct effect on commute satisfaction. As a result, previous studies might have overestimated the effects of travel time and travel mode choice on travel satisfaction. This indicates that at least partial effects of travel duration and travel mode on travel satisfaction are through the path of commute time dissonance. Strategies that help to alleviate the commute time dissonance might be more important than solely focusing on reducing commute time. In other words, reducing commute time is necessary but not sufficient for improved commute satisfaction, as some people might want longer commutes than their actual commute time.

To reduce the dissonance between actual and ideal commute time, people may either change (especially reduce) their commute duration, or change (especially improve) their attitudes towards travel. Planning strategies, such as jobs-housing balance and compact development, will not only help to reduce commute distance, but will also reduce commute duration and encourage active travel, which in turn will reduce commute time dissonance and improve commute satisfaction. It might also be possible to make changes to people's ideal commute time. For this, it is necessary to make travel time more comfortable, productive or enjoyable. For active travel, this can relate to safe and comfortable cycling lanes and sidewalks. Free Wi-Fi and power sockets on trains and buses can make 
travel time more productive for public transport users. For car users, forms of driving assistance can reduce drivers' tiredness, and make travel time more enjoyable. By making travel time more enjoyable/productive, people's ideal commute time might increase and, as a result, attitudes towards travel in general might also improve. In other words, travel time can be compressed as making trips more rewarding might create the experience of a trip passing more quickly without actually reducing travel time. Improving travel time becomes not only a matter of reducing travel time, it also becomes a matter of investing in ways to make trips more enjoyable and productive (Watts and Lyons, 2010; Watts and Urry, 2008). By doing so, the group of respondents having longer than preferred commute trips will become smaller, positively affecting commute satisfaction. Given that changing the actual commute time might involve relocating home or job locations and will not be an option for many workers, changing the perception of travel time and attitudes towards commuting might be the key to reduce the dissonance between actual and ideal commute time. Reducing people's commute time dissonance might improve their subjective well-being both directly through improved commute satisfaction, and indirectly through positive spill-over effects on work satisfaction and work productivity ( $\mathrm{Ma} \& \mathrm{Ye}, 2019$ ). Figure 7 gives an overview of how we have analysed commute time dissonance and its effects on commute satisfaction in this study, and how a situation of dissonance and low travel satisfaction can be converted into low levels of dissonance and high levels of satisfaction.

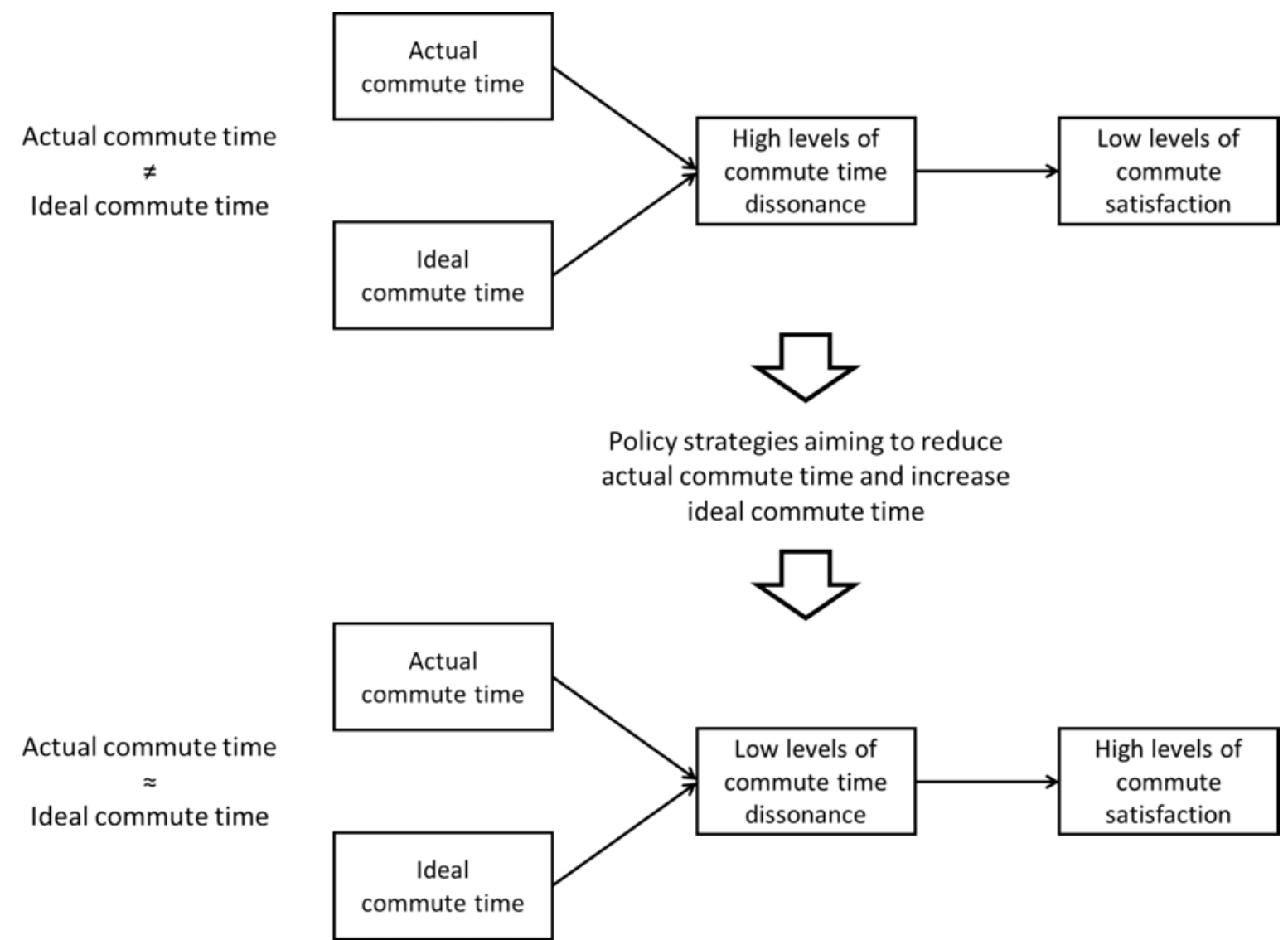

Figure 7. Effects of commute time dissonance on commute satisfaction.

Although this study provides valuable insights into how people perceive their commute trips and how this is affected by their actual and ideal commute time, this study has some limitations resulting in various avenues for future research. First, our sample is not representative of the working populations of Xi'an. For instance, as the length of the survey is long (18+ minutes), we might not be able to recruit 
busy workers with a high value of time, resulting in a biased sample. Second, people might have various ideal commute times for different travel modes. For example, cycling preferences might result in a person having an ideal commute time of 20 minutes when cycling, but only an ideal commute time of 10 minutes when driving. As a result, future studies might want to ask respondents' ideal commute time for various modes. Third, this study uses cross-sectional data, which prevents to make rigorous causal inferences. The found results indicated that commute time dissonance leads to lower commute satisfaction, while those with lower commute satisfaction might also adjust their commute behaviour or travel attitudes to achieve a consonance between travel behaviour and attitudes. Future research may explore these reciprocal relationships between commute time dissonance and travel satisfaction in greater detail. Finally, more complex methodologies might be appropriate for future studies. Structural equation modelling, for instance, might analyse both direct and indirect effects (through travel time dissonance) of travel mode and trip duration on travel satisfaction, thereby analysing the mediating effect of travel time dissonance on travel satisfaction.

\section{Acknowledgments}

We thank the McKenzie Postdoctoral Fellowship from the University of Melbourne for providing the funding support to conduct the survey. We also thank the two anonymous reviewers for their constructive comments on earlier drafts of the paper. Any errors, however, are solely those of the authors.

\section{References}

Choi, J., Coughlin, J.F., D'Ambrosio, L., 2013. Travel time and subjective well-being. Transportation Research Record: Journal of the Transportation Research Board 2357, 100-108.

Clark, B., Chatterjee, K., Martin, A., Davis, A., 2019. How commuting affects subjective wellbeing. Transportation. In press. https://doi.org/10.1007/s11116-019-09983-9

De Vos, J., 2018. Do people travel with their preferred travel mode? Analysing the extent of travel mode dissonance and its effect on travel satisfaction. Transportation Research Part A 117, 261-274.

De Vos, J., 2019a. Analysing the effect of trip satisfaction on satisfaction with the leisure activity at the destination of the trip, in relationship with life satisfaction. Transportation 46 (3), 623-645.

De Vos, J., 2019b. Satisfaction-induced travel behaviour. Transportation Research Part F 63, 12-21.

De Vos, J., Mokhtarian, P.L., Schwanen, T., Van Acker, V., Witlox, F., 2016. Travel mode choice and travel satisfaction: bridging the gap between decision utility and experienced utility. Transportation 43 (5), 771-796.

De Vos, J., Schwanen, T., Van Acker, V., Witlox, F., 2013. Travel and subjective well-being: A focus on findings, methods and future research needs. Transport Reviews 33 (4), 421-442.

De Vos, J., Schwanen, T., Van Acker, V., Witlox, F., 2015. How satisfying is the Scale for Travel Satisfaction. Transportation Research Part F 29, 121-130.

De Vos, J., Witlox, F., 2017. Travel satisfaction revisited. On the pivotal role of travel satisfaction in conceptualising a travel behaviour process. Transportation Research Part A 106, 364-373. 
Ettema, D., Gärling, T., Eriksson, L., Friman, M., Olsson, L.E., Fujii, S., 2011. Satisfaction with travel and subjective well-being: Development and test of a measurement tool. Transportation Research Part F: Psychology and Behaviour 14, 167-175.

Ettema, D., Gärling, T., Olsson, L.E., Friman, M., 2010. Out-of-home activities, daily travel, and subjective well-being. Transportation Research Part A 44 (9), 723-732

Festinger, L., 1957. Theory of Cognitive Dissonance. Stanford University Press, Stanford.

Frey, B.S., 2018. Economics of Happiness. Springer, Cham.

Handy, S., Cao, X., Mokhtarian, P., 2005. Correlation or causality between the built environment and travel behavior? Evidence from Northern California. Transportation Research Part D: Transport and Environment 10, 427-444.

Higgins, C.D., Sweet, M.N., Kanaroglou, P.S., 2018. All minutes are not equal: travel time and the effects of congestion on commute satisfaction in Canadian cities. Transportation 45 (5), 1249-1268.

Jain, J., Lyons, G., 2008. The gift of travel time. Journal of Transport Geography 16, 81-89.

Kahneman, D., Krueger, A.B., Schkade, D.A., Schwarz, N., Stone, A.A., 2004. A survey for characterizing daily life experience: the day reconstruction method. Science 306 (5702), 1776-1780.

LaJeunesse, S., Rodríguez, D. A., 2012. Mindfulness, time affluence, and journey-based affect: exploring relationships. Transportation Research Part F 15 (2), 196-205.

Lancée, S., Veenhoven, R., Burger, M., 2017. Mood during commute in the Netherlands: What way of travel feels best for what kind of people? Transportation Research Part A 104, 195-208.

Legrain, A., Eluru, N., El-Geneidy, A., 2015. Am stressed, must travel: The relationship between mode choice and commuting stress. Transportation Research Part F 34, 141-151.

Lyons, G., Jain, J., Holley, D., 2007. The use of travel time by rail passengers in Great Britain. Transportation Research Part A 41 (1), 107-120.

Ma, L. and Ye, R., 2019. Does daily commuting behavior matter to employee productivity?. Journal of Transport Geography, 76, pp.130-141.

Metz, D., 2008. The myth of travel time saving. Transport Reviews 28 (3), 321-336.

Milakis, D., Cervero, R., van Wee, B., Maat, K., 2015. Do people consider an acceptable travel time? Evidence from Berkeley, CA. Journal of Transport Geography 44, 76-86.

Mokhtarian, P.L., 2018. Subjective well-being and travel: retrospect and prospect. Transportation. In press. https://doi.org/10.1007/s11116-018-9935-y

Mokhtarian, P.L., Papon, F., Goulard, M., Diana, M., 2015. What makes travel pleasant and/or tiring? An investigation based on the French National Travel Survey. Transportation 42 (6), 1103-1128.

Mokhtarian, P.L., Salomon, I., 2001. How derived is the demand for travel? Some conceptual and measurement considerations. Transportation Research Part A 35 (8), 695-719.

Morris, E.A., Guerra, E., 2015a. Are we there yet? Trip duration and mood during travel. Transportation Research Part F 33, 38-47.

Morris, E.A., Guerra, E., 2015b. Mood and mode: does how we travel affect how we feel? Transportation 42 (1), 25-43

Morris, E.A., Zhou, Y., 2018. Are long commutes short on benefits? Commute duration and various manifestations of well-being. Travel Behaviour and Society 11, 101-110. 
Olsson, L.E., Gärling, T., Ettema, D., Friman, M., Fujii, S., 2013. Happiness and satisfaction with work commute. Social Indicators Research 111 (1), 255-263.

Ory, D.T., Mokhtarian, P.L., 2005. When is getting there half the fun? Modeling the liking for travel. Transportation Research Part A 39 (2-3), 97-123.

Páez, A., Whalen, K., 2010. Enjoyment of commute: A comparison of different transportation modes. Transportation Research Part A 44 (7), 537-549.

Redmond, L.S., Mokhtarian, P.L., 2001. The positive utility of the commute: modeling ideal commute time and relative desired commute amount. Transportation 28, 179-205.

Russell, M., Mokhtarian, P.L., 2015. How real is a reported desire to travel for its own sake? Exploring the 'teleportation' concept in travel behaviour research. Transportation 42 (2), 333-345.

Smith, O., 2017. Commute well-being differences by mode: Evidence from Portland, Oregon, USA. Journal of Transport \& Health 4, 246-254.

Song, Y., Zenou, Y. and Ding, C., 2008. Let's not throw the baby out with the bath water: the role of urban villages in housing rural migrants in China. Urban studies, 45(2), pp.313-330.St-Louis, E., Manaugh, K., van Lierop, D., El-Geneidy, A., 2014. The happy commuter: a comparison of commuter satisfaction across modes. Transportation Research Part F 26, 160-170.

Stutzer, A., Frey, B.S., 2008. Stress that Doesn't Pay: The Commuting Paradox. The Scandinavian Journal of Economics 110, 339-366.

Watts, L., Lyons, G., 2010. Travel remedy kit. In: Büsher, M., Urry, J., Witchger, K., (Eds.) Mobile methods. Routledge, Abingdon, pp. 189-213.

Watts, L., Urry, J., 2008. Moving methods, travelling times. Environment and Planning D 26 (5), 860874.

Ye, R., 2017. Impact of Individuals' Commuting Trips on Subjective Well-being: Evidence from Xi'an. UCL (University College London).

Ye, R., Titheridge, H., 2015. Impact of Individuals' Commuting Trips on Subjective Well-being-Evidence from Xi'an, China, Transportation Research Board 94th Annual Meeting.

Ye, R., Titheridge, H., 2017. Satisfaction with the commute: The role of travel mode choice, built environment and attitudes. Transportation Research Part D 52B, 535-547.

Ye, R., Titheridge, H., 2019. The determinants of commuting satisfaction in low-income population: A case study of Xi'an, China. Travel Behaviour and Society. In press. https://doi.org/10.1016/j.tbs.2019.01.005

Zhu, J., Fan, Y., 2018a. Commute happiness in Xi'an, China: Effects of commute mode, duration, and frequency. Travel Behaviour and Society 11, 43-51.

Zhu, J., Fan, Y., 2018b. Daily travel behavior and emotional well-being: Effects of trip mode, duration, purpose, and companionship. Transportation Research Part A 118, 360-373. 


\section{Appendix}

Scatter-plot of ideal versus actual commute time by commute modes
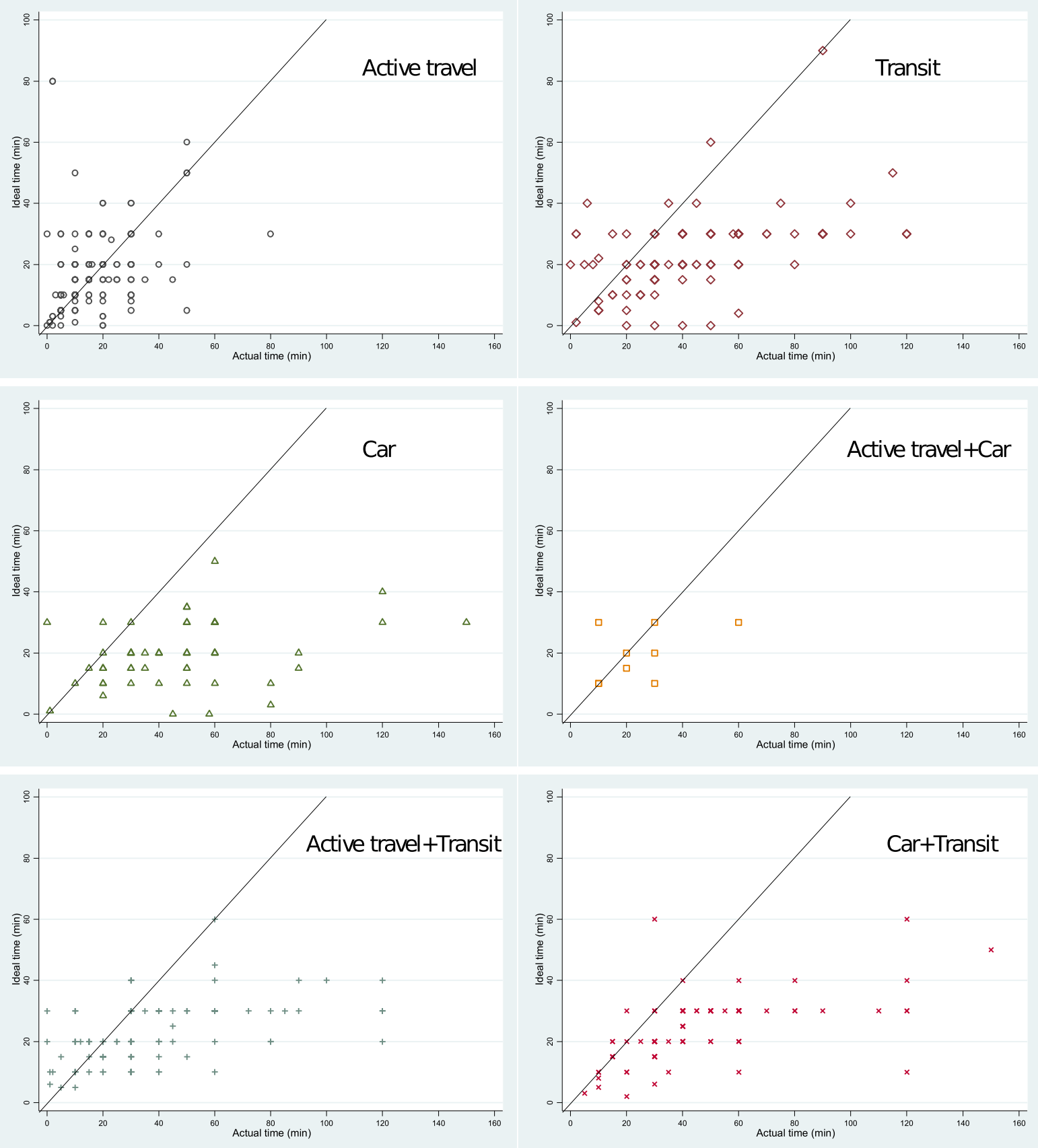